\title{
Comparative study of the digastric and the stylohyoid muscles between wild boars (Sus scrofa scrofa) and domestic swine (Sus scrofa domesticus): revisiting the gross anatomy
}

\author{
Henrique Inhauser Riceti Magalhães ${ }^{1}$, Jeferson Borges Barcelos ${ }^{2}$, Fabiano Braz Romão ${ }^{3}$, \\ Tânia Ribeiro Junqueira Borges ${ }^{2}$, Roseâmely Angélica de Carvalho-Barros ${ }^{4}$, \\ Maria Angelica Miglino, ${ }^{1}$ Frederico Ozanam Carneiro e Silva ${ }^{2}$, Lucas de Assis Ribeiro ${ }^{2}$ \\ ${ }^{1}$ Department of Surgery, School of Veterinary Medicine and Animal Sciences, University of São Paulo, São Paulo, ${ }^{2}$ Animal Anatomy Laboratory, School \\ of Veterinary Medicine and Animal Sciences, Federal University of Uberlândia, Uberlândia, ${ }^{3}$ Animal Anatomy Laboratory, School of Veterinary \\ Medicine, University Center of Patos de Minas, Patos de Minas, ${ }^{4}$ Anatomy Laboratory, School of Biological Sciences, Federal University of Catalão, \\ Catalão, Brazil
}

\begin{abstract}
Considering Suidae Familie as a perfect and viable experimental biomedical model for research applied to human medicine, it has been sought to describe the comparative anatomy of the digastric and the stylohyoid muscles between boars and domestic swine. Heads of Sus scrofa scrofa and Sus scrofa domesticus were dissected. The digastric muscle presented only one muscle belly as anatomical component of a tendinous origin in the jugular process of the occipital bone, and muscle insertion in the midventral edge of the caudal two thirds of the body of the mandible. Thus, its function is fundamentally associated with the lowering and the retracting of the mandible which, by the way, can deliver greater muscle power at lesser energy expense. For the stylohyoid muscle, the tendinous origin was in the laterocaudal edge of the dorsal third of the stylohyoid bone. The muscle insertion - primarily, was in the lateral and caudal edges from the mid third portion up to the ventral extremity of the thyrohyoid bone, and secondarily as a laterolateral aponeurotic blade which would unite, in a bilateral manner, an insertion that was common to the sternohyoid, the geniohyoid, and the mylohyoid muscles in a median ventral region. This morphology were similar to the two specimens studied expanding the information available, which were completely unknown for the suidae until the moment.
\end{abstract}

Key words: Comparative anatomy, Deglutition, Hyoid bone, Mastication, Suidae

Received November 17, 2020; 1st Revised December 30, 2020; 2nd Revised January 12, 2021; Accepted January 13, 2021

Corresponding author:

Henrique Inhauser Riceti Magalhães (i)

Department of Surgery, School of Veterinary Medicine and Animal Sciences, University of São Paulo, São Paulo 05508-270, Brazil

E-mail: inhauser@usp.br

\section{Introduction}

Comparative anatomy describes the animals structurewise and erects a foundation for them to be classified. On that way, it has been possible to demonstrate the genetic relation of several groups, whilst elucidating the meaning of many structural phenomena that are still quite obscure at times [1]. In respect of the wild species, that science has been expanding most likely due to its capacity of evaluating 
the relations between similar structures and their functions in taxonomically different groups. Within that context, it becomes extremely important to understand the relations between the biome and its components, as well as the adaptations and adjustments which could perchance be there among and with other living beings [2].

Upon our analyzing a particular gender or species, a muscle can be either absent or represented in a distinct manner, or yet dislocated to another muscle group [1]. From that premise, it is certain that the topographic morphology of the muscles is tied to the functionality of the same [2]. Ergo, the distribution and the action of muscles differ throughout the several classes of mammals, whilst exemplifying an evolutionary adaptation pursuant to their activity [1].

In spite of their not acting in an independent fashion [3], the muscles of mastication are grouped in accordance with their function of moving the mandible in different planes or directions [4] as they provide for the mechanical degradation of food [5]. Thus, knowledge pertinent to each one of those muscles is a necessary premise for the understanding of their participation in mastication [6], and when skewed towards the relation between these structures and the bone portions, it allows for the comprehension of the dietary habits and the ecological niche of every animal, whilst highlighting similarities with the other organisms that share into the same habitat and resources [2].

Assuming that craniofacial research has significantly advanced over the past decade [7], and that the suidae have come to be the most viable experimental biomedical model for comparative investigation of several organs and systems applied to the human medicine [8] including in the medical area mentioned [9]; the studies which involve the structures in the head are becoming ever more important. When considered evolutionarily akin species, the similarities, when they do exist, qualify new animals as alternatives for the experimental studies.

Then, it has been sought to describe comparatively the anatomy of the digastric and the stylohyoid muscles of boars and domestic swine, whilst demonstrating the points of origin and the muscle insertions plus the possible actions performed by each of them over mastication. It is also inferred from both the specific similarity between these individuals, and the morphological and topographical differences in regard of the other species presented in the literature including the humam species.

\section{Materials and Methods}

Ten heads of juvenile Sus scrofa scrofa (five male and five female) and ten heads of young-aged crossbred Sus scrofa domesticus (three male and seven female) have been used. The material comprises the didactic-scientific collection of the Animal Anatomy Laboratory of the Federal University of Uberlândia (UFU-Brazil).

The arterial system of each specimen has been marked with the use of a latex-based aqueous solution at $50 \%$ (polyvinyl acetate, $\mathrm{C}_{4} \mathrm{H}_{6} \mathrm{O}_{2}$ ) stained with specific red pigment (water-based dye). To that end, a five-centimeter transverse incision was made at the level of the dorsal third of the ninth left intercostal space and, upon removal of the cutaneous muscle of the trunk, of the latissimus dorsi, of the external and internal intercostal muscles, and of the parietal pleura, the descending thoracic aorta was isolated and cannulated with cranial and caudal orientation for the subsequent instillation of the said product.

Now, the fixation has taken place upon intramuscular, subcutaneous, and intracavitary injections of a formaldehyde aqueous solution at $10 \%\left(\mathrm{CH}_{2} \mathrm{O}\right.$; Chemco Indústria e Comércio Ltda, Hortolândia, São Paulo, Brazil), and the ensuing immersion of the cadavers in opaque vessels with a solution of the same concentration - wherein they would remain for 20 days prior to their being manipulated again.

Two sections were performed to finish the preparation of the material studied. The first was performed transversewise, on the mid third of the neck, so the head would be isolated from the rest of the body, whilst the second section at the level of the median sagittal plane produced the hemiheads for dissection. The access for visualization of the muscles commenced by means of the opening of the skin and of the cutaneous muscle of the face, with caudal-rostral orientation. Upon exposure of the masseter muscle, the same would be removed from the masseteric fossa, so that the regions of angle and ramus of the mandible were extricated which contributed for the visualization of the insertion of the digastric muscle. Subsequently, the parotidoauricularis muscle and the parotid salivary gland were removed in order to facilitate the identification of the origins of the digastric and the stylohyoid muscles. Upon removal of the mandibular salivary gland and of the mandibular lymph nodes, the isolation and the verification of the insertions of the stylohyoid muscle were made possible.

The anatomic nomenclature adopted for the description 
of the results had been in accordance with the International Committee on Veterinary Gross Anatomical Nomenclature [10]. The study was approved by the Ethics Committee on the Use of Animals of the Federal University of Uberlândia (UFU-Brazil), protocols number 103/13 and 81/14.

\section{Results}

In the boars - and in nine of ten domestic swine scrutinized - the digastric muscle would present one muscle belly as anatomic component, positioned in a longitudinal fashion and displaying a spindle-shaped characteristic, which inserted in the midventral edge of the caudal two thirds of the body of the mandible, just rostral to the angular incisure (Fig. $1 \mathrm{~A}, \mathrm{~B})$. In the remaining domestic swine female, two muscle bellies individualized by a middle tendon had been observed. The insertion of the same occurred through the rostral belly, had also taken place in the midventral edge of the caudal two thirds of the body of the mandible, just rostral to the angular incisure (Fig. 1C).

In both morphologies found for the species regarded, the muscular origin would always take place projected in ventrorostral orientation as from the jugular process of the occipital bone (Fig. 1). In the case of the digastric muscle with two bellies in the domestic swine, that would be essentially muscular by means of the caudal muscle belly (Fig. 1C). Upon consideration of the digastric muscle with one belly in both species, the long tendon of origin would directly relate with the muscle belly of insertion (Fig. 1A, B). Still, given the topography and the distribution of the muscle fibers, the possible set of motions feasible to any of those muscles entails the lowering and the retraction of the mandible.

Yet, the stylohyoid muscle of boars and domestic swine would present a tendinous origin in the laterocaudal edge of the dorsal third of the stylohyoid bone and, after its having stretched in ventromedial orientation and in contact with the tendon of origin of the digastric muscle, it inserted in the guise of a muscle belly with lightly oblique and spindleshaped fibers, which were laterocaudally set from the mid third as far as the ventral extremity of the thyrohyoid bone. This muscle also attached in a rostroventral manner in a region of common insertion to the sternohyoid, the geniohyoid, and the mylohyoid muscles, which displayed a short aponeurotic morphology. The structure in question would stretch laterolaterally in such manner that the counterlateral muscles of common insertion ended up joining bilaterally in that site, at the level of a median ventral spot (Figs. 2-4).

It is presumed that the stylohyoid muscle primordially aids in the stabilization and positioning of the larynx, whilst also acting as a synergist over the processes of contraction
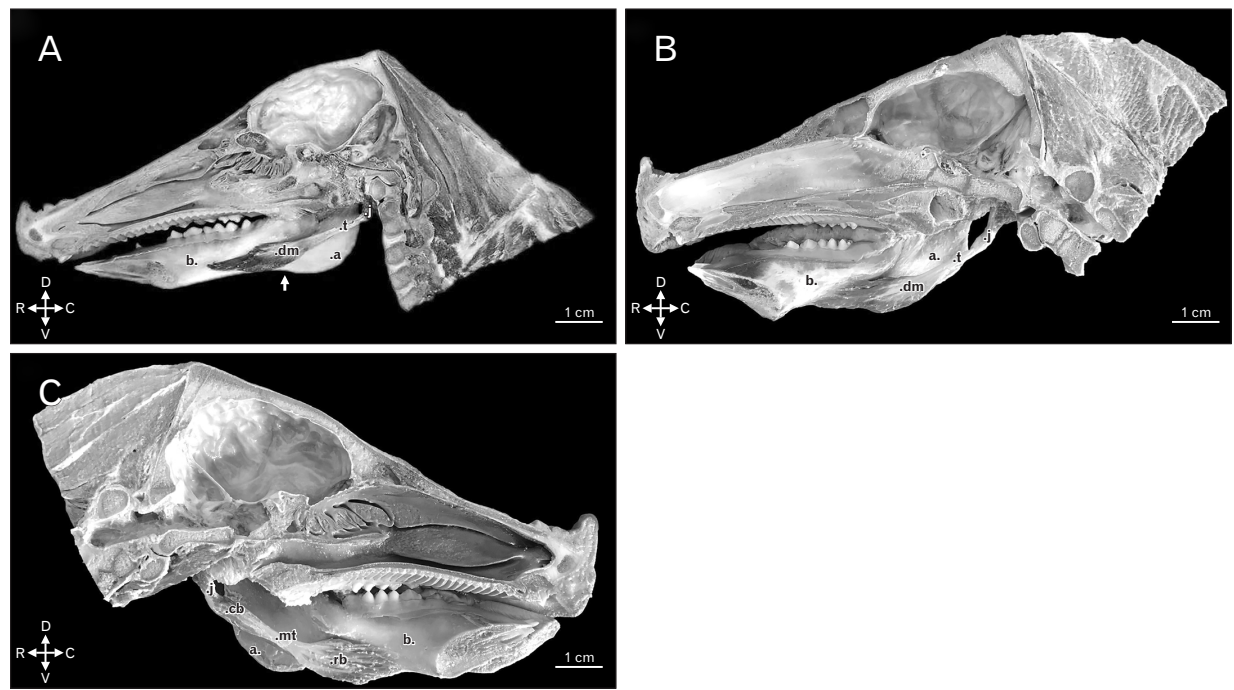

Fig. 1. (A) Medial view of right hemihead of boar, $\mathrm{dm}$ and the $\mathrm{t}$ of the digastric muscle. Other structures: $\mathrm{j}$, a, b, and angular incisure of the mandible (white arrow). Animal direction: D, V, R, and C. (B) Medial view of right hemihead of domestic swine dm and the $t$ of the digastric muscle. Other structures: j, a, and b. Animal direction: D, V, R, and C. (C) Medial view of left hemihead of domestic swine highlighting the $\mathrm{rb}$ and $\mathrm{cb}$ bellies, and the $\mathrm{mt}$ of the digastric muscle. Other structures: $\mathrm{j}$, a, and b. Animal direction: D, V, R, and C. a, angle of the mandible; b, body of the mandible; C, caudal; cb, caudal belly; D, dorsal; dm, highlighting the single muscle belly; j, jugular process of the occipital bone; mt, middle tendon; $\mathrm{R}$, rostral; rb, rostral belly; $\mathrm{t}$, tendon of origin; $\mathrm{V}$, ventral. 

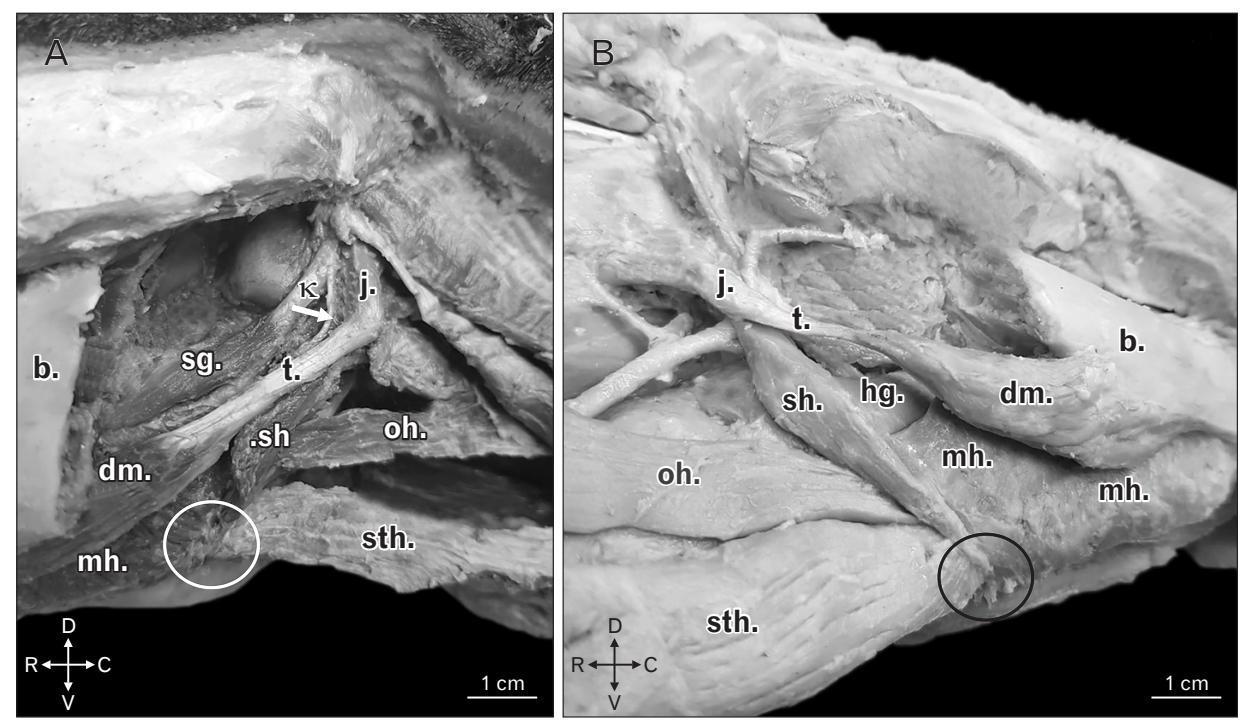

Fig. 2. (A) Left ventrolateral view of boar head highlighting the common insertion, and in the form of an aponeurotic blade (white circle), of sh, $\mathrm{sth}$, and $\mathrm{mh}$. There is also demonstration of the tendon of origin of the stylohyoid muscle (white arrow) as from the $\kappa$. Other structures: $b, t, d m$, sg, oh, and j. Animal direction: D, V, R, and C. (B) Right ventrolateral view of a domestic swine head highlighting the common insertion, and in the form of an aponeurotic blade (black circle), of sh, sth, and mh. Other structures: b, t, dm, hg, oh, and j. Animal direction: D, V, R, and C. b, body of the mandible; C, caudal; D, dorsal; dm, single belly of the digastric muscle; hg, hyoglossus muscle; j, jugular process of the occipital bone; mh, mylohyoid muscles; oh, omohyoid muscle; R, rostral; sg, styloglossus muscle; sh, stylohyoid; sth, sternohyoid; $t$, tendon of origin of the digastric muscle; $\mathrm{V}$, ventral; $\kappa$, laterocaudal edge of the dorsal third of the stylohyoid bone.
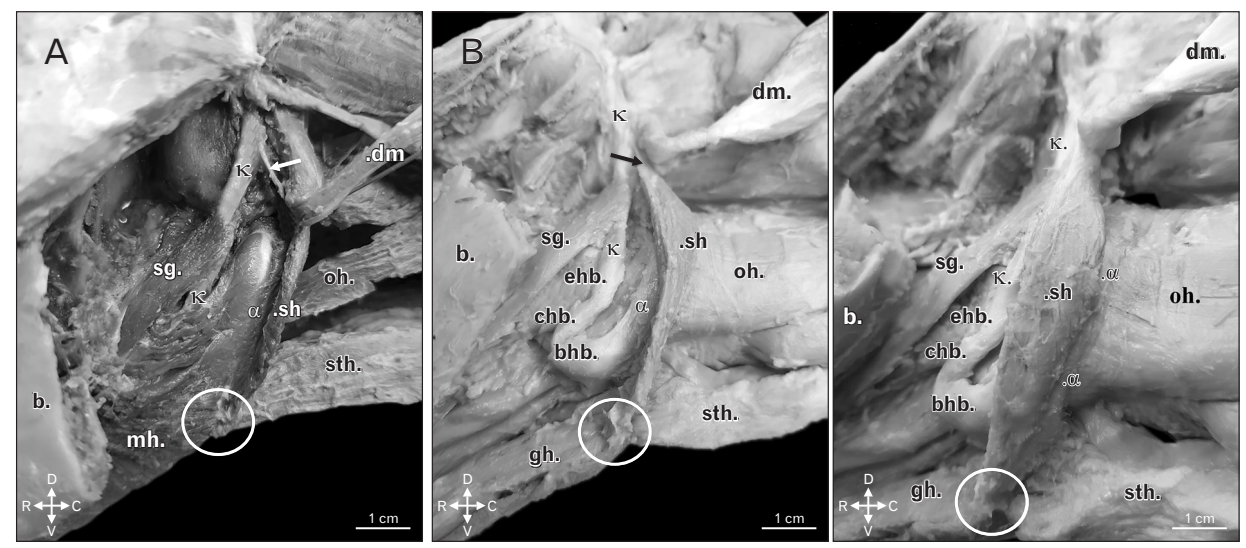

Fig. 3. (A) Left ventrolateral view of boar head highlighting the insertion of the sh in the lateral and caudal edges from the mid third as far as the ventral extremity of the $\alpha$. There is also demonstration of the tendon of origin of the stylohyoid muscle (white arrow) as from the $\kappa$. Other structures: common insertion, and in the form of an aponeurotic blade (white circle), of sh, sth, and the mh, b, dm, oh, and sg. Animal direction: D, $\mathrm{V}, \mathrm{R}$, and C. (B) Left lateroventral view of a domestic swine head highlighting the insertion of the sh in the lateral and caudal edges from the mid third as far as the ventral extremity of the $\alpha$. There is also demonstration of the tendon of origin of the stylohyoid muscle (black arrow) as from the $\kappa$. Other structures: common insertion, and in the form of an aponeurotic blade (white circle), of sh, sth, and gh, b, dm, oh, sg, bhb, chb, and ehb. Animal direction: D, V, R, and C. b, body of the mandible; bhb, basihyoid bone; C, caudal; chb, ceratohyoid bone; D, dorsal; dm, digastric muscle open with caudodorsal orientation; ehb, epihyoid bone; hg, hyoglossus muscle; j, jugular process of the occipital bone; mh, mylohyoid muscles; oh, omohyoid muscle; R, rostral; sg, styloglossus muscle; sh, stylohyoid muscle; sth, sternohyoid; $t$, tendon of origin of the digastric muscle; V, ventral; $\alpha$, thyrohyoid bone; $\kappa$, laterocaudal edge of the dorsal third of the stylohyoid bone. 

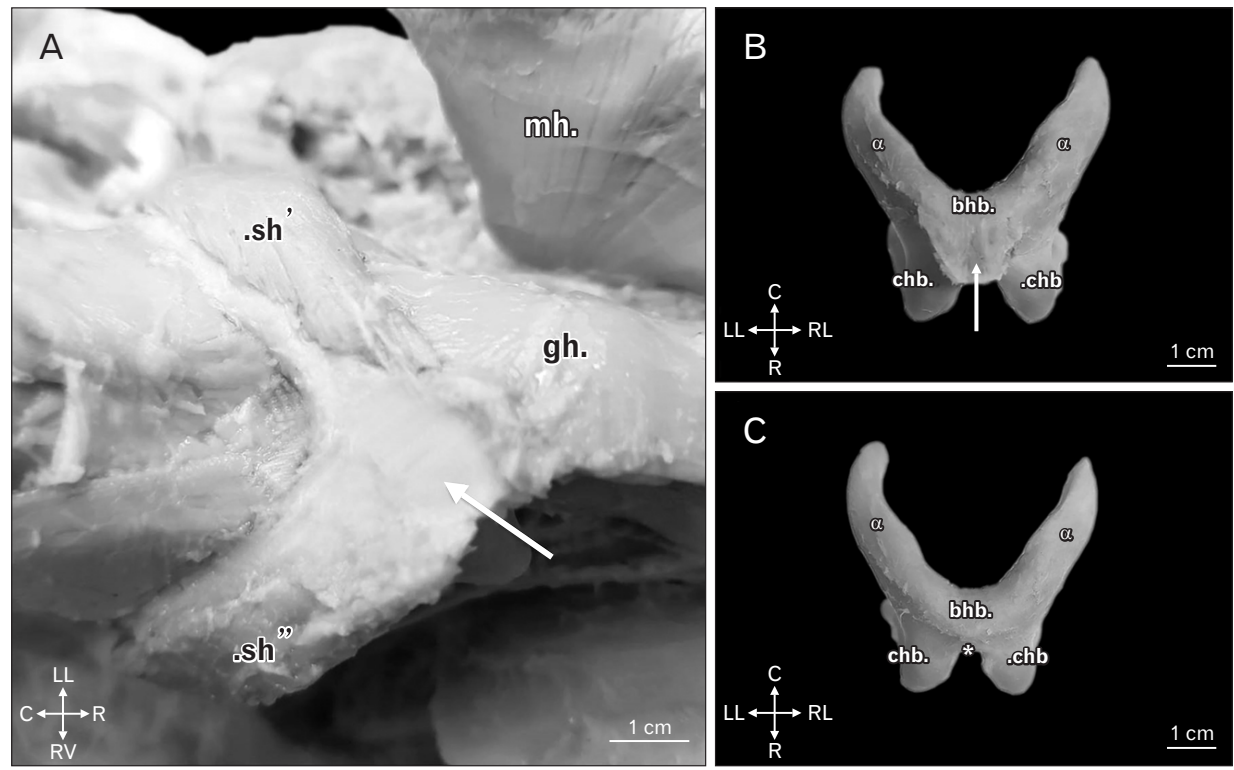

Fig. 4. (A) Ventral view of a domestic swine head highlighting the common insertion with short and aponeurotic morphology, stretching with laterolateral orientation to be a point of common insertion to muscles positioned in a counterlateral manner, bilaterally uniting the same in a medioventral fashion (white arrow). Other structures: sh', sh", mh, and gh. Animal direction: LL, RL, R, and C. (B) Ventral view of the hyoid bone of a domestic swine highlighting the common insertion with short and aponeurotic morphology of the stylohyoid, the sternohyoid, the geniohyoid, and the mylohyoid muscles (white arrow). Other structures: bhb, chb, and $\alpha$. Animal direction: LL, RL, R, and C. (C) Ventral view of the hyoid bone of a domestic swine upon removal of the aponeurotic blade of insertion of the stylohyoid, the sternohyoid, the geniohyoid, and the mylohyoid muscles, highlighting the point of attachment of the same $\left(^{*}\right)$. Other structures: bhb, chb, and $\alpha$. Animal direction: LL, RL, R, and C. bhb, basihyoid bone; C, caudal; chb, ceratohyoid bone; gh, geniohyoid muscle; LL, left lateral; mh, mylohyoid muscle open with laterodorsal orientation; R, rostral; RL, right lateral; sh', left stylohyoid muscle; sh", ight stylohyoid muscle; $\alpha$, thyrohyoid bone.

and relaxation of the digastric muscle. Due to its insertion so wide and complex, it also acts as a supporting floor of the hyoid bone for the maintenance of its position over the moving of the tongue, especially upon the phase of deglutition.

\section{Discussion}

The digastric muscle, as indicated by the very name, possesses two muscle bellies [11-13], and is presented with that denomination in several species.

In regard of the your origin, in boars and domestic swine alike, it has taken place in a tendinous fashion departed from the jugular process of the occipital bone, just as described by Getty [1] for ruminants and swine. In equines and domestic carnivores that have taken place directly through its muscle fibers, also attached in the jugular process of the occipital bone $[1,14,15]$.

Upon analyzing the origin of the digastric muscle in a number of wild animals, it was noticed that the same had also taken place in the jugular process of the occipital bone for the crab-eating raccoon (Procyon cancrivorus) [16], the black-eared opossum (Didelphis marsupialis), the moonrat (Echinosorex gymnurus), the white-tailed deer (Odocoileus virginianus), the fox squirrel (Sciurus niger), and the brown rat (Rattus norvegicus) [17]. However, for the North American river otter (Lutra canadensis), the sea otter (Enhydra lutris), the striped skunk (Mephitis mephitis), the North American badger (Taxidea taxus), the american pine marten (Martes americana), the wolverine (Gulo luscus), and the american mink (Mustela vison), apart from the structure quoted, the said muscle would also originated from the jugulomastoid crist [18]. Yet, for the caspian seal (Phoca caspica), the reported region was the ventral surface of the auditory bulla of the occipital bone [19], whilst, for the kangaroo (Macropus robustus), the paraoccipital process of the occipital bone was reported [20].

Spataru et al. [21] whilst studying the red squirrel (Sciurus vulgaris), and Ferreira et al. [22] whilst analyzing the blackcapped capuchin (Cebus apella), have pointed out that the digastric muscle would originate in the paracondylar process of the occipital bone however, in the first species mentioned the origin would also involve the caudoventral region of the 
tympanic bulla. Yet, in rabbits, the anatomic region quoted by Muhl and Newton [23] has been the paramastoid process at the base of skull. In humans, Madeira [12], Standring [24], and Khan and Bordoni [13] would claim the mastoid incisure of the temporal bone as being the point of muscle origin.

In the domestic ruminants $[1,11]$, equines $[1,15,25]$, crabeating raccoon [16], red squirrel [21], black-eared opossum, moonrat, white-tailed deer, fox squirrel, and brown rat [17], the digastric muscle would pursue its path from its caudal belly, by means of a strong intermediate tendon, to have its continuity rostrally interrupted by the emergence of the rostral belly of the digastric muscle. Peculiarly in equines, the caudal belly would present the occipitomandibular part set laterally and inserted in the caudal edge of the angle of the mandible $[1,15,25,26]$.

Yet, in the domestic carnivores, only one tendinous intersection $[1,27]$, small and hardly noticeable, would represent the intermediate tendon and indicate the digastric nature of the muscle [14]. For the mustelidae studied by Scapino [18], quite similar a description to that had been given, whilst, in the caspian seal the caudal belly would insert in the ventral region of the rostral belly of the digastric muscle itself [19].

Save the different points of origin of the digastric muscle, the description made by Ferreira et al. [22] for the blackcapped capuchin bore great resemblance to that which had been reported by Madeira [12], Moore et al. [28], Standring [24], O'Daniel [29], Al-Missri and Khalili [30], and Khan and Bordoni [13] in humans. In such instances, the rostral and caudal bellies, anterior and posterior in humans, would also be united by an intermediate tendon in common, albeit attached to the hyoid bone by fibers of the fasciae from the cervical region.

In rabbits and kangaroos, only one muscle belly would respectively be observed by Muhl and Newton [23] and Tomo et al. [20]. In the domestic species, the digastric muscle, after its tendo-aponeurotic origin, would stretch unhindered to insert with its muscle fibers in the medial surface of the mandible [23]. Yet, in the wild species, that muscle would be comprised by a fascicle, rounded and small in its origin, but wider, thick, and tendinous in its insertion [20].

For the domestic swine, Getty [1] referenced such muscle just as the occipitomandibular part of the digastric muscle, whilst Kyllar et al. [7], in mentioning a muscular composition of two continuous bellies would use the denomination of digastric muscle. Before the indetermination, and now supported by the representations and descriptions made herein for boars and domestic swine, it is known that the muscle belly present is single, and whilst corroborating with Getty [1] and Kyllar et al. [7] in regard of its insertion in the midventral edge of the body of the mandible, it is assumed that the similarities between those species are highly relevant.

It has been worth to mention observing an anatomic variation in regard of the number of muscle bellies present in a female swine specimen, which characterized one muscle with two muscle bellies individualized by a middle tendon. In humans, morphological variations of the digastric muscle are common [31] and usually related to supranumeric bellies [32-34], and to differences in the form and site of insertion [35-37]. This reporting is always crucial, since those variations may interfere with the interpretation of imagery scans [35] and in the clinical and surgical procedures of the region [38].

Now, in respect of the insertion of the digastric muscle through its rostral belly, in accordance with Getty [1], Singh [26], and König and Liebich [15] for equines, and with Turnbull [17] for the black-eared opossum, this muscle has taken place through the aforementioned anatomic point for the two specimens of suidae. In the domestic ruminants it has been observed in the medial $[1,15]$ and ventral edges of the body of the mandible [11]. For the domestic carnivores, Getty [1] and Budras et al. [14] have reported that said attachment would be visualized in the ventral edge of the mandible, whilst König and Liebich [15] claimed the insertion on the ventromedial surface of that osseous structure, opposed to the lower canine tooth. Still for the domestic carnivores, Evans and DeLahunta [27] has indicated only the region of the body of the mandible as the area of insertion just as Pereira et al. [16] did whilst studying specimens of crab-eating raccoon. In mustelids, the reported regions would be the ventral, lateral, and medial edges of the body of the mandible, ventralwise to the first or the second lower molars until nearly the level of the mandibular foramen [18].

Spataru et al. [21] described that, in the red squirrel, the attachment of the rostral belly of the digastric muscle would take place together with the mylohyoid and geniohyoid muscles upon the merger of the same in the intermandibular space. Yet, in the moonrat, the muscle insertion has been visualized on the ventrolateral surface of the mandible, ventralwise to the lower molars. Nevertheless, for the whitetailed deer, the insertion would mostly take place in the ventromedial area of the mandible, rostralwise to the attachment of the medial pterygoid muscle and, in a lesser scale, 
medialwise in the ramus of the mandible. In the fox squirrel and the brown rat, the ventromedial edge of the rostral third of the body of the mandible has been verified as the site of muscle insertion [17]. In the caspian seal the same would take place on the medial and ventromedial surfaces of the body of the mandible after a first attachment in the angular process of the mandible [19].

Ferreira et al. [22] reported in the black-capped capuchin, the rostral belly would insert in the body of the mandible, whilst stretching out from its incisive ventral edge as far as the ventral edge of the molar portion of the bone. In humans the attachment would take place through the anterior belly in the digastric fossa of the mandible $[13,24,29,30]$.

For the identification of the possible action of a given muscle and the consequent motion executed in the body of the mandible, we may quote that the topographical and directional observation of the fibers is of the utmost importance. As from that analysis in the boars and in the domestic swine it has been possible to suggest that the digastric muscle would perform in the lowering and in the retracting of the mandible, thus partially corroborating the information recorded in the better part of the literature on domestic animals $[1,14,15,23,26,27,39,40]$, on wild animals $[16,18,19]$, and on humans $[13,24,29]$, wherein reports on that latter action are mostly lacking in the descriptions pertinent to the digastric muscle.

Nevertheless, Madeira [12] have claimed that, in human kind, upon it is sliding by the loop that attaches it to the hyoid bone, said muscle contracts as a whole and drags the mandible backwards, thus contributing for the lowering of the same in synergy with the lateral pterygoid muscle. In wild animals, motions of backward dragging associated with the amplification of the temporomandibular articulation have been described only for the red squirrel [21]. In suidae, the ventral limit of the very long paroccipital process extends far below the palate and reaches the ramus of the mandible, which causes the digastric muscle to exert a backward traction on the mandible [39]. Furthermore, the functions of elevation of the hyoid bone over deglutition $[29,41]$ and the lateralization of the mandible during the opening of the mouth [40] have also been mentioned.

In quite broad a manner, the muscles may be classified in regard of origin and insertion $[4,11]$, of the number of muscle bellies present, of the position in the skeleton [11], of the orientation of the fibers $[4,11]$, and of the shape and function [4]. So, just as noted by Ribeiro et al. [42], we reaffirm the inconvenience of using the term 'digastric' to name the muscle under scrutiny in boars, hence only one muscle belly has been observed in that species. Ergo, it is suggested that the denomination of mandibular retractor muscle can be adopted based on the muscle functionality upon analysis of its topography, rather than on the number of muscle bellies present as has been made for the other animals. By the way, given the similarity of this muscle in the domestic swine, the use of the same criteria for that species becomes pertinent even for any other species which has morphologically and physiologically similar a muscle to this one.

Still on the guidance for anatomical denomination, it has been noticed that the Nomina Anatomica Veterinaria [10] and the Terminologia Anatomica [43] contradict one another in regard of the description of the 'intermediate' tendon of the digastric muscle, in view of the distribution of the muscle as a whole upon analyzing the specimens in anatomical position.

In veterinary science, upon our referring to the indicative terms of position and orientation of three different structures distributed along a longitudinal axis, cranial, middle, and caudal are applied should the same be located along the head, neck, and trunk (whilst altering to hands, feet, and when two or more structures of the head are regarded) [15]. In a similar fashion, the same rules are applied for humans, albeit the terms used are anterior, middle, and posterior when the structures are observed in a sagittal axis [44]. Therefore, the characterization of the said tendon as the middle tendon of the digastric muscle becomes valid, hence the same is located middlewise to the rostral and caudal bellies of both domestic and wild animals (longitudinal axis), and to the anterior and posterior bellies of humans (sagittal axis).

Yet, in respect of the anatomy of the stylohyoid muscle in the domestic ruminants, its origin has taken place by a long and slim tendon attached to the muscle angle of the stylohyoid bone. The insertion is muscular and occurs in the lateral end of the basihyoid bone [1]. Now, in the domestic carnivores, König and Liebich [15] have claimed that such muscle would originate from the temporal bone, and insert in the thyrohyoid bone. In equines, the origin has taken place in a tendinous fashion in the muscle angle of the dorsal end of the thyrohyoid bone, and upon the formation of a spindleshaped muscle belly inserted by a tendon in the rostral portion of the same bone [1].

In humans, this muscle is attached by a tendon to the posterior face of the stylohyoid process, next to the base of the 
same and, upon its having stretched as far as the body of the hyoid bone, at the junction with the greater horn, may end in the digastric or supra or, even, infra-hyoid muscles [24, 45]. It is pointed out that, in the boars and in the domestic swine, the stylohyoid muscle originated by a long tendon in the laterocaudal edge of the dorsal third of the stylohyoid bone and inserted as a muscle belly - firstly, in the lateral and caudal edges form the mid third as far as the ventral extremity of the thyrohyoid bone; and in a secondary fashion, rostroventrally in a region of insertion of the sternohyoid, the geniohyoid, and the mylohyoid muscles, which presented a short and aponeurotic morphology, and which has laterolaterally stretched so that the counterlateral muscles of common insertion ended up by uniting bilaterally in that site at the level of a median ventral spot.

Generally, in the domestic animals the stylohyoid muscle moves the hyoid bone and the larynx in a caudodorsal manner [15], whilst in humans its function is associated to the raising and the retracting of the hyoid bone, with the consequent stretching of the floor of the mouth [24, 45]. Together with the other hyoid muscles, it also stabilizes the hyoid bone, aids in the opening of the mouth, in the flexing of the neck, and in the production of acute sounds [45]. In the boars and in the domestic swine, the possible function of the muscle in question enfolds the stabilization and the positioning of the larynx, whilst also performing in synergy with the digastric muscle and as a floor of fixation and support for the hyoid bone during motion of the tongue in the process of deglutition. It is important to highlight that no relationship of contact between the hyoid bone and the digastric muscle has been observed in the suidae.

For the equines, Getty [1], Budras et al. [25], Singh [26], and König and Liebich [15] informed that the 'intermediate' tendon of the digastric muscle had perforated the tendon of insertion of the stylohyoid muscle, wherein the same would be endowed with a synovial sheath [1]. Yet, in humans, the 'intermediate' tendon also crosses the stylohyoid muscle next to its insertion $[12,24]$ although it binds, right after, to the body and the greater horn of the hyoid bone by means of a fibrous sling [28], whereby it slides in the anterior and posterior directions $[12,28]$ in a manner similar as that of a pulley $[28,46]$, and at times it also presents a synovial sheath [24].

With such grounds, we are able to infer that, respectively in equines and humans, the stylohyoid muscle and the fibrous sling also act as a muscular annex in the guise of a reflection pulley for the digastric muscle whilst providing for a retransmission of its power over mastication and facilitating the performance of their actions. For boars and domestic swine it is proposed that, even upon lack of observation of a specific muscular annex for the structures regarded in this study, the morphology of the digastric muscle permits its functions to be carried out at the requirement of less energy spent, hence the presence of a more elongated tendon of origin in lieu of a second muscle belly can create a more efficient mechanism for the storing and the release of the elastic energy created by the tensioning of that tissue which also provides for greater muscle strength, as has been suggested by Witvrouw et al. [47]. This characteristic is potentiated by the topographical and biomechanical relationship of the digastric muscle with the tendon of origin of the stylohyoid muscle, as this one also acts physically in the guise of a lever arm for that muscle.

It is concluded that unlike the vast majority of the species presented in the literature, for boars and domestic swine the digastric muscle presented only one muscle belly as an anatomical component, of a tendinous origin in the jugular process of the occipital bone and muscle insertion in the midventral edge of the caudal two thirds of the body of the mandible. It is believed that this morphology can favor the storing and the release of elastic energy created by the tendinous tensioning whilst providing for greater muscle power at lesser energy expense, which would facilitate the breaking of harder foods. This muscle acts in the lowering and the retracting of the mandible.

For the stylohyoid muscle the tendinous origin in the laterocaudal edge of the dorsal third of the stylohyoid bone, and the muscle insertion - primarily - in the lateral and caudal edges from the mid third as far as the ventral extremity of the thyrohyoid bone, and secondarily as a laterolateral aponeurotic blade which bilaterally united a common insertion with the sternohyoid, the geniohyoid, and the mylohyoid muscles in a median ventral region have been similar for the two suidae specimens. Thus, it can be presumed that this muscle possibilitates a greater degree of stability in the positioning of the larynx whilst also performing in the guise of a lever arm in synergy with the digastric muscle, and as a floor of fixation and support for the hyoid bone during motion of the tongue upon deglutition. By comparison, the morphology observed was different from that which had been described for the other animals and humans, thus expanding the bulk of information available in regard of their functions - completely unknown for the suidae until then. 


\section{ORCID}

Henrique Inhauser Riceti Magalhães:

https://orcid.org/0000-0001-9151-8160

Jeferson Borges Barcelos:

https://orcid.org/0000-0001-8307-8513

Fabiano Braz Romão:

https:/orcid.org/0000-0002-8873-7001

Tânia Ribeiro Junqueira Borges:

https://orcid.org/0000-0002-0231-1764

Roseâmely Angélica de Carvalho-Barros:

https:/orcid.org/0000-0002-9510-0308

Maria Angelica Miglino:

https://orcid.org/0000-0003-4979-115X

Frederico Ozanam Carneiro e Silva:

https://orcid.org/0000-0002-6241-2364

Lucas de Assis Ribeiro:

https://orcid.org/0000-0002-6635-0156

\section{Author Contributions}

Conceptualization: HIRM, FOCS, LAR. Data acquisition: HIRM, JBB, LAR. Data analysis or interpretation: HIRM, RACB, MAM, FOCS, LAR. Drafting of the manuscript: HIRM, FBR, TRJB. Critical revision of the manuscript: RACB, MAM, FOCS, LAR. Approval of the final version of the manuscript: all authors.

\section{Conflicts of Interest}

No potential conflict of interest relevant to this article was reported.

\section{Acknowledgements}

The authors thank to the National Council for Scientific and Technological Development (CNPq) and to Coordination for the Improvement of Higher Education Personnel (CAPES), for the financial support to the authors.

\section{References}

1. Getty R. Sisson/Grossman: the anatomy of the domestic animals. 5th ed. Philadelphia: Saunders; 1975.

2. Oliveira C, Teixeira RAP, Conchalo WL. [A contextualized approach to human and comparative anatomy]. Núcleos de Ensino 2004:291-310. Portuguese.
3. Matsunaga K, Usui A, Yamaguchi K, Akita K. An anatomical study of the muscles that attach to the articular disc of the temporomandibular joint. Clin Anat 2009;22:932-40.

4. Silva ACJ, Ferreira LR, Silva MHM, Cavalcante MG, Monteiro MM, Nascimento HB, Pereira APC, Maschka FG. Músculos da mastigação: aspectos anatômicos e importância médicocirúrgica (em vídeo) [Internet]. Recife: Universidade Federal Rural de Pernambuco; 2019 [cited 2019 Sep 12]. Available from: http:// www.eventosufrpe.com.br/jepex2009/cd/resumos/r1125-1.pdf.

5. Marchesan IQ. Motricidade oral: visão clínica do trabalho fonoaudiológico integrado com outras especialidades. São Paulo: Pancast; 1993.

6. Sicher H, Du Brul EL. Anatomia bucal. 6th ed. Rio de Janeiro: Guanabara Koogan; 1977.

7. Kyllar M, Stembírek J, Putnová I, Stehlík L, Odehnalová S, Buchtová M. Radiography, computed tomography and magnetic resonance imaging of craniofacial structures in pig. Anat Histol Embryol 2014;43:435-52.

8. Papadaki ME, Troulis MJ, Glowacki J, Kaban LB. A minipig model of maxillary distraction osteogenesis. J Oral Maxillofac Surg 2010;68:2783-91.

9. Štembírek J, Kyllar M, Putnová I, Stehlík L, Buchtová M. The pig as an experimental model for clinical craniofacial research. Lab Anim 2012;46:269-79.

10. International Committee on Veterinary Gross Anatomical Nomenclature. Nomina anatomica veterinaria. 6th ed. Hanover: World Association of Veterinary Anatomists; 2017.

11. Godinho HP, Cardoso FM, Nascimento JF. Anatomia dos ruminantes domésticos. Belo Horizonte: UFMG; 1981.

12. Madeira MC. Anatomia da face: bases anatomofuncionais para a prática odontológica. 8th ed. Sao Paulo: Sarvier; 2012.

13. Khan YS, Bordoni B. Anatomy, head and neck, suprahyoid muscle [Internet]. Treasure Island, FL: StatPearls Publishing; 2020 [cited 2019 Dec 16]. Available from: https://www.ncbi. nlm.nih.gov/books/NBK546710/.

14. Budras KD, McCarthy PH, Fricke W, Richter R, Horowitz A, Berg R. Anatomy of the dog: an illustrated text. 5th ed. Hannover: Schlütersche; 2007.

15. König HE, Liebich HG. Veterinary anatomy of domestic animals: textbook and colour atlas. 7th ed. New York: Thieme Medical Publishers; 2020.

16. Pereira KF, Souza DR, Ferreira LS, Ribeiro AR. Aspectos morfológicos dos músculos da cabeça e pescoço do mão pelada (Procyon cancrivorus). SaBios: Rev Saúde Biol 2012;7:1-8.

17. Turnbull WD. Mammalian masticatory apparatus. Chicago: Field Museum of Natural History; 1970.

18. Scapino RP. Function of the digastric muscle in carnivores. J Morphol 1976;150:843-59.

19. Endo H, Sakata S, Arai T, Miyazaki N. The muscles of mastication in the caspian seal (Phoca caspica). Anat Histol Embryol 2002;31:262-5.

20. Tomo S, Tomo I, Townsend GC. Digastric muscle of the kangaroo: a comparative anatomical study. Anat Rec 1998;251:34650 . 
21. Spataru C, Spataru M, Vulpe V, Lazar M. The peculiarities of the masticator muscles in rodents. Arq Bras Med Vet Zootec 2013;65:749-56.

22. Ferreira JR, Pinto Júnior N, Kajita D, Cirqueira DS, Nogueira DJ. [Study of muscle digastric descriptive and topographical anatomy in primates (Cebus apella, Linnaeus, 1766)]. Braz J Vet Res Anim Sci 2005;42:113-21. Portuguese.

23. Muhl ZF, Newton JH. Change of digastric muscle length in feeding rabbits. J Morphol 1982;171:151-7.

24. Standring S. Gray's anatomy: the anatomical basis of clinical practice. 41st ed. Edinburgh: Churchill Livingstone; 2015.

25. Budras KD, Sack WO, Rock S. Anatomy of the horse. Hannover: Schlütersche; 2009.

26. Singh B. Dyce, sack, and Wensing's textbook of veterinary anatomy. 5th ed. St. Louis: Elsevier; 2018.

27. Evans HE, DeLahunta A, Miller ME. Guide to the dissection of the dog. 8th ed. St. Louis: Elsevier; 2017.

28. Moore KL, Dalley AF, Agur AMR. Clinically oriented anatomy. 8th ed. Philadelphia: Lippincott Williams and Wilkins; 2018.

29. O’Daniel TG. Understanding deep neck anatomy and its clinical relevance. Clin Plast Surg 2018;45:447-54.

30. Al-Missri MZ, Khalili YA. Anatomy, head and neck, submental triangle [Internet]. Treasure Island, FL: StatPearls Publishing; 2020 [cited 2019 Dec 16]. Available from: https://www.ncbi. nlm.nih.gov/books/NBK545296/.

31. Kim SD, Loukas M. Anatomy and variations of digastric muscle. Anat Cell Biol 2019;52:1-11.

32. Zdilla MJ, Soloninka HJ, Lambert HW. Unilateral duplication of the anterior digastric muscle belly: a case report with implications for surgeries of the submental region. J Surg Case Rep 2014;2014:rju131.

33. Harvey JA, Call Z, Peterson K, Wisco JJ. Weave pattern of accessory heads to the anterior digastric muscle. Surg Radiol Anat 2015;37:1001-4.

34. Šink Ž, Umek N, Cvetko E. Cross-over type of supernumerary digastric muscle. Folia Morphol (Warsz) 2019;78:647-50.

35. Mascaro MB, Picoli LC, Santos FM, Bonsi AB, Souza MR, Prosdócimi FC. Anatomical variation of the anterior belly of the digastric muscle: case report and clinical implications. J Morphol Sci 2011;28:72-5.

36. Kalniev M, Krastev D, Krastev N, Vidinov K, Veltchev L, Apostolov A, Mileva M. A rare variation of the digastric muscle. Clujul Med 2013;86:327-9.

37. Das S, Ghafar NA, Othman F, Kamaruddin A, Suhaimi FH. Anomalous belly of digastric muscle: gross anatomy with clinical implications. Middle East J Sci Res 2014;21:733-5.

38. De-Ary-Pires B, Ary-Pires R, Pires-Neto MA. The human digastric muscle: patterns and variations with clinical and surgical correlations. Ann Anat 2003;185:471-9.

39. Hou S, Deng T, He W, Chen SQ. Foraging behavior of Chleuastochoerus (Suidae, Artiodactyla): a case study of skull and mandible morpho-functional analysis. Sci China Earth Sci 2014;57:988-98.

40. Weijs WA, Dantuma R. Functional anatomy of the masticatory apparatus in the rabbit (Oryctolagus Cuniculus L.). Neth J Zool 1981;31:99-147.

41. Rowlerson A, Mascarello F, Veggetti A, Carpene E. The fibretype composition of the first branchial arch muscles in Carnivora and Primates. J Muscle Res Cell Motil 1983;4:443-72.

42. Ribeiro LA, Luz MM, Silva FOC, Borges TRJ, Silva Z, Santos LA. Anatomia dos músculos da mastigação de Javali (Sus scrofa scrofa Linnaeus, 1758). O Anatomista 2016;7:150.

43. The Federative International Programme for Anatomical Terminology. Terminologia anatomica. 2nd ed. New York: Thieme; 2019.

44. Dangelo JG, Fattini CA. Anatomia humana basica. 2nd ed. Sao Paulo: Atheneu; 2002.

45. Rathee M, Jain P. Anatomy, head and neck, stylohyoid muscle [Internet]. Treasure Island, FL: StatPearls Publishing; 2020 [cited 2019 Dec 16]. Available from: https://www.ncbi.nlm.nih. gov/books/NBK547653/.

46. Lippert LS. Clinical kinesiology and anatomy. 6th ed. Philadelphia: Davis Company; 2017.

47. Witvrouw E, Mahieu N, Roosen P, McNair P. The role of stretching in tendon injuries. Br J Sports Med 2007;41:224-6. 